\title{
SUSTAINABLE MANAGEMENT OF DEBRIS FROM THE L'AQUILA EARTHQUAKE: ENVIRONMENTAL STRATEGIES AND IMPACT ASSESSMENT
}

\author{
Antonio Basti * \\ Department of Architecture, University of Chieti-Pescara, Viale Pindaro 42, 65100 Pescara, Italy
}

Article Info:
Received:
23 January 2018
Revised:
8 May 2018
Accepted:
11 June 2018
Available online:
30 June 2018
Keywords:
Earthquake
Debris management
Sustainability
Environmental design
Life Cycle Assessment

\section{INTRODUCTION}

Debris management is one of the key points of the highly complex system of governance supporting the reconstruction of historic centres damaged by earthquakes. This is demonstrated by on-going debate over the most appropriate ways to remove, transport, sort, store and recycle recovered materials.

From this point of view, criteria of environmental sustainability, including the reduction of new raw materials, waste, energy consumption and emissions related to the transportation of materials to and from landfills, and the maximum reuse of Construction and Demolition Waste (C\&DW), represent best practices on which to base local regulatory instruments for the management of waste removal activities (Braungart M., McDonough W., 2002).

More generally, as concerns the sustainable management of C\&DW, national and European rules and regulations provide some good starting points: Thematic Strategies for the Sustainable Use of Natural Resources (European Commission, COM (2005) 670), Public Procurement for a Better Environment (European Commission, COM (2008) 400), European Directive on Waste (European Commission,
Directive 2008/98/CE), Italian rules on $30 \%$ use of recycled materials and products in public procurement (Italian Ministry of the Environment, 2003) and the recovery of $70 \%$ of C\&DW by 2020 (Italian Government, 2010).

In addition, Italy's recent Public Procurement Code (Italian Government, 2016) issued mandatory "Minimal environmental criteria for the design and management of public administration buildings and sites" (Italian Ministry of the Environment, 2015).

Several authors have addressed the issue of sustainable C\&DW management, examining aspects related to various ways of reusing waste as Secondary Raw Materials (SRM), the performance that can be obtained from building elements made from recycled aggregates (Ossa A. et al., 2016; Fan H.C. et al., 2016; Señas L. et al., 2016; Puthussery J.V. et al., 2017), as well as the environmental impacts of various types of collection, transportation and end of life scenarios (landfill, recycling, reuse), based on Life Cycle Assessments (LCA) (Butera S. et al., 2015; Silva A. et al., 2017).

More specifically, other authors have studied ways of managing earthquake debris, focusing on the usefulness of an effective operational plan (Lauritzen E.K., 1998; Brown 
(GWP) values, as published by the Intergovernmental Panel on Climate Change (IPCC, 2001; Hischier R., Weidema B., 2010). At the same time, it was considered appropriate to refer to a time horizon of 100 years, in order to understand the middle-term effects of atmospheric lifetimes of different gases.

As known, GWPs are an index for estimating relative global warming contributions due to atmospheric emission of a particular GHG compared to the emission of carbon dioxide, used as a reference value with a GWP of 1 . The measuring value is the carbon dioxide equivalent $\left(\mathrm{CO}_{2} \mathrm{eq}\right)$ expressed in kg (Albritton D. L., Meira-Filho L. G., 2001). management activities.

With this objective in mind, the study applied the abovementioned approach to a specific case study: the rubble generated by the earthquake that struck the city of L'Aquila in April 2009. The study focused on a homogeneous area, known as AREA 5, which includes the towns of Brittoli, Bussi sul Tirino, Civitella Casanova, Cugnoli, Montebello di Bertona, Ofena and Popoli. Beginning with a physical and infrastructural analysis of this territory, the study extend its attention to the rubble produced by this earthquake, compared to regional and national data. The analysis was also extended to the network of public and private companies authorised to treat C\&DW materials, to understand their location and capacity to manage the debris produced by this earthquake. Finally, the study deepened the understanding of the debris management programme and legislative framework issued after the earthquake, to examine the feasibility of subsequent management hypotheses.

All of this information was used to define a set of possible rubble management schemes that were then compared. In particular, the centralised model indicated by the Reconstruction Commissioner, and a more widespread model based on the transfer of C\&DW to the nearest authorised collection companies present in the area, selected based on the criterion of the shortest distance from the production site. This criterion was adopted as it allows for a reduction in the distances travelled by individual vehicles, travel times, traffic, loads and anticipated wear on road infrastructures.

The two models were compared in both physical and environmental terms. In the first case this involved assessing the distances travelled, and in the second assessing Greenhouse Gas (GHG) emissions created by transportation.

To simulate environmentally sound behaviour, it was considered important to make reference to the internationally codified Life Cycle Assessment (LCA) methodology (ISO 14040, 2006). In particular, considering the aim of the study, it was considered useful to adopt an expedited approach (screening LCA), more suitable to the development of a comparative assessment and the identification of improvement actions at a political stage. For this purpose, the study made use of LCA software (SIMAPRO, PRE' Consultant) and inventory data from literature or data banks associated with the software (ECOINVENT, PRE' Consultant). Moreover, it was considered appropriate to develop the assessments by relying on the IPCC 2001 (Climate Change) method, based on the characterisation of different GHG emissions according to their Global Warming Potential

\section{RESULTS AND DISCUSSION}

As mentioned, the study focused on the district known as the "L'Aquila Earthquake Crater", comprised of towns in varying states of destruction following the April 2009 earthquake.

To correctly appreciate the extent of the "rubble" produced by this event, it is worth noting that the Italian production of C\&DW in that year was approximately $30,000,000 \mathrm{~m}^{3}$ (Fischer C., Werge M., 2009) and that of the Abruzzo region in the range of $633,000 \mathrm{~m}^{3}$ (Laraia R., 2011). The Institute for Building Technologies-Italian National Research Council (ITC-CNR) estimates the amount of rubble from the collapses and demolitions related to the L'Aquila earthquake at approximately 2,000,000-2,650,000 $\mathrm{m}^{3}$, with some $1,125,640-1,305,617 \mathrm{~m}^{3}$ in the town of L'Aquila alone ( $49 \%$ of the total). More specifically, AREA 5 had no particular problems related to the presence of rubble on public roadways to be removed, with the exception of the historic centre of Ofena, where the collapse of part of a housing block obstructed a street in this area. Nevertheless, the management of C\&DW also concerns the repairing and/or reconstruction of buildings and spaces, both public (road works, infrastructures, pilot projects) and private, whose scale can only be evaluated following the presentation of Recovery and Consolidation projects.

Given such a huge volume to be dealt with in such a short time, and the necessity to ensure accessibility to and from construction sites in the historic centres, the companies operating in the province of L'Aquila authorised to treat C\&DW materials provided an initial estimate of annual capacity of approximately $406,000 \mathrm{~m}^{3}$ /year. So, it appears evident that more temporary landfill, selection and treatments sites would be required, together with sites to be prepared for the storage of inert materials intended for reuse/recycling and possible disposal in non-dangerous and non-recyclable waste landfills after selection.

\subsection{The Institutional Rubble Management Programme}

To regulate flows of materials and debris, three different management sites (Figure 1) were identified by the reference legislative framework issued after the earthquake (Commissioner Delegated to Reconstruction, Decrees 18/2010, 49/2011, 51/2011; Italian Prime Minister, 2011):

The former "EX TEGES" site in PAGANICA, for temporary rubble storage and selection, as well as the treat- 


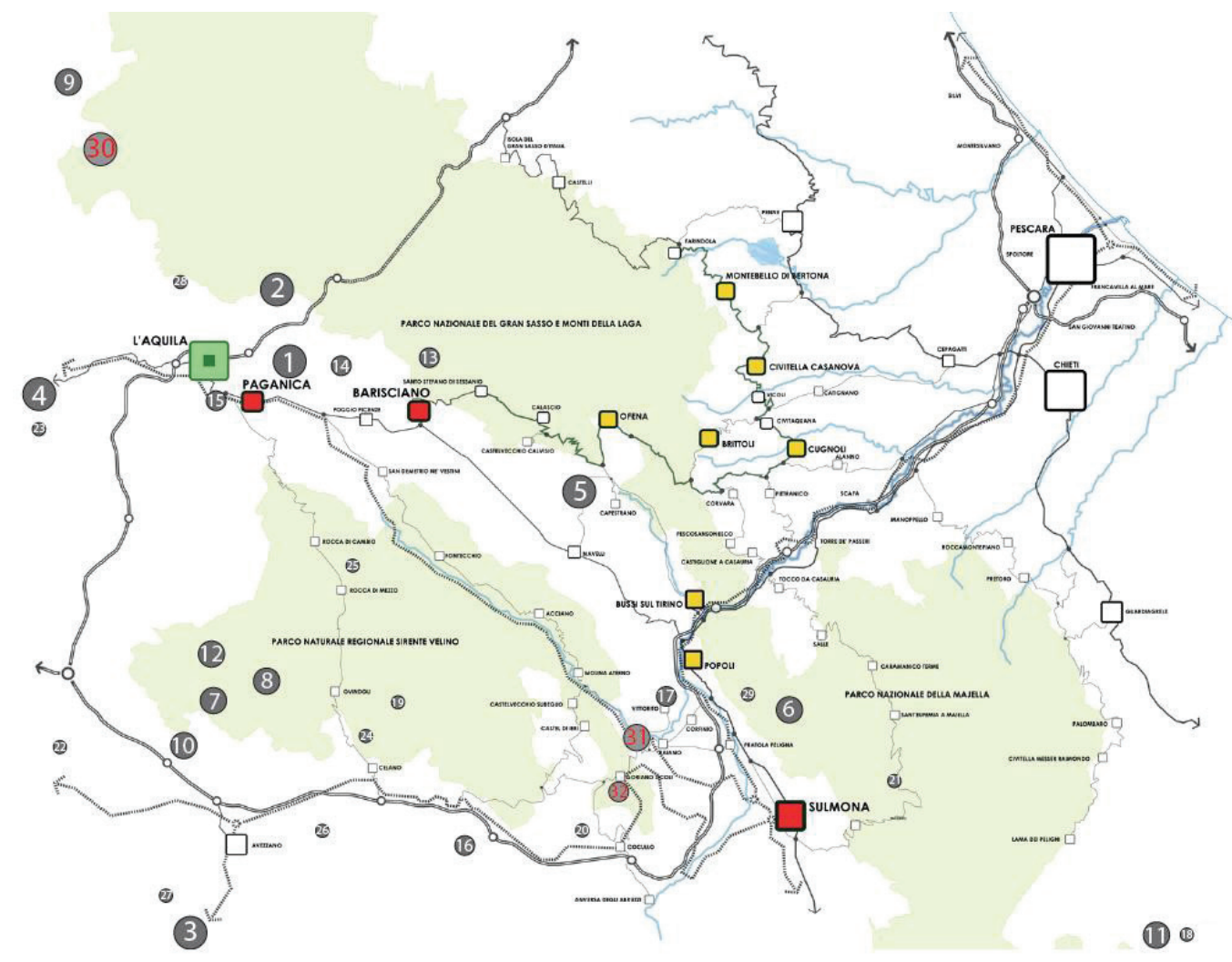

FIGURE 1: Temporary storage, treatment and disposal sites identified by Presidential Ordinance OPCM 3923/2011 et seq. (in red) and inert material collection and storage companies in the Province of L'Aquila, arranged by size (in grey).

ment, collection and storage of inert materials from collapses and demolitions for reuse;

- The TECHNOLOGICAL HUB in BARISCIANO, for temporary storage, treatment and disposal of waste from collapses, as well as from the demolition of damaged buildings;

- The "COGESA" LANDFILL in SULMONA, for the disposal of non-hazardous waste from the selection and treatment of rubble not suitable for recovery or reuse.

Furthermore, due to the high density of these historical centres, guaranteeing the ease of movement and temporary storage of rubble required individual municipalities to adopt specific Rubble Management Plans. These Plans identify one or more dedicated public areas, depending on the number of planned demolitions, easily accessible to collection and transportation vehicles. In these areas debris is arranged by homogeneous code categories, according to the Italian and European Waste Catalogue (EWC) (European Commission, 2000; Italian Government, 2006) and placed in metallic or fabric bins (i.e. big bags). To facilitate these activities and limit the public spaces required for temporary storage, private subjects must proceed with the selective demolition, separation and storage of C\&DW on building sites.

Finally, the transportation of both public and private C\&DW to treatment sites is assigned to the fire brigade, military or ASM SpA (L'Aquila's Multiservice Company), or to registered national environmental management companies. In particular, the public supply chain concerns rubble from collapsed buildings, demolitions of dangerous buildings or building works conducted by public authorities and are considered urban solid waste (Italian Government, 2009). Instead, private supply chain concerns rubble generated by private repair or reconstruction works, considered special waste to be managed under the normal collection and disposal programme.

\subsection{The Impact Assessment of Organisational Choices}

Without prejudice to the need to verify the environmental compatibility and legal compliance of temporary storage and treatment sites for rubble and C\&D inert materials (activities outside the scope of this simulation), it is however possible to evaluate the physical and environmental impacts of organisational choices (Basti A., 2010), such as the selection of C\&DW disposal sites.

The first hypothesis investigated is the "centralised model" indicated by the Reconstruction Commission and identified as SCENARIO 1. It contemplates the collection of C\&DW at the Technological Hub in Barisciano dedicated to the temporary storage, treatment and disposal of waste from collapses and/or demolitions of damaged buildings. This solution presents some advantages owing to its location in the same location as the landfill for non-recoverable waste. In fact, this option means that this waste would not have to be transported to the "COGESA" LANDFILL in Sulmona for the disposal of the non-hazardous and/or non-recoverable or non-recyclable residues (Figure 2).

The second hypothesis investigated is the "widespread model" identified as SCENARIO 2, which contemplates the 


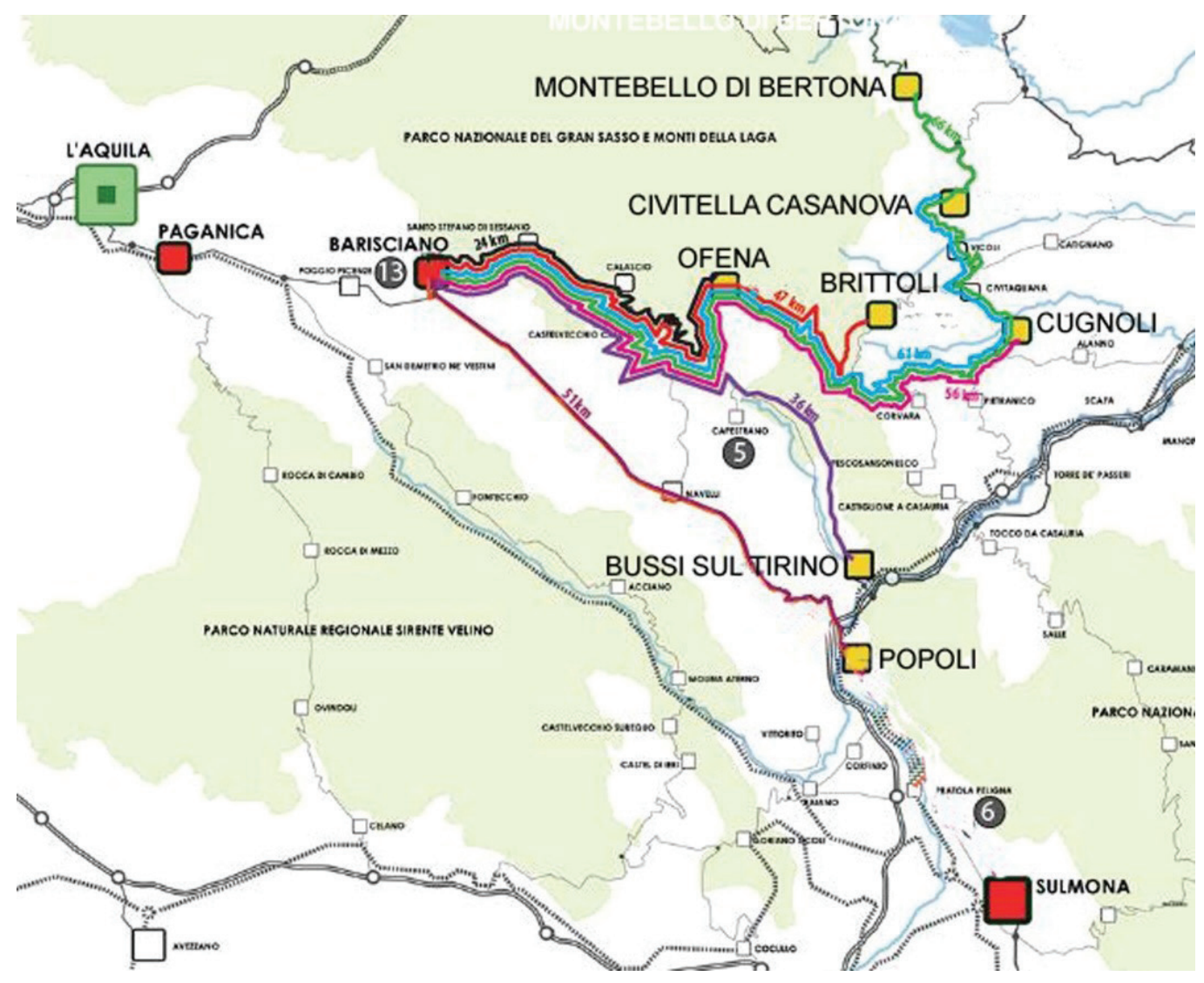

FIGURE 2: Identification of transportation flows for C\&DW produced by reconstruction works in the towns of Homogeneous Area 5 (in yellow). SCENARIO 1: storage at the Technological Hub in Barisciano (AQ).

collection of C\&DW by the nearest authorised collection companies present in the area, selected using the criterion of the shortest distance from the production site. Applying this criterion to the case study reveals that the towns at an altitude of $500 \mathrm{~m}$ above sea level (Brittoli, Civitella Casanova, Cugnoli, Montebello di Bertona and Ofena) and Bussi sul Tirino would benefit if they turned to Company 5 in Capestrano, while Popoli would benefit by turning to Company 6 in Pratola Peligna (Figure 3).

Comparing the two hypotheses by distance travelled, it is possible to note that in SCENARIO 1 the distance is approximately $284 \mathrm{~km}$, while in SCENARIO 2 it is close to $151 \mathrm{~km}$. However, to this last distance it is necessary to add the additional transport of non-recoverable waste from Capestrano to Barisciano (24 km) and from Pratola Peligna to Sulmona (12 km), for a total of 36 additional kilometres. For this reason the total distance of SCENARIO 2 is roughly $187 \mathrm{~km}$. In light of this, it can be stated that in the second hypothesis the distance travelled by each vehicle could be reduced by about $133 \mathrm{~km}$, or roughly $34 \%$. This also means a consequent reduction in travel times, as well as loads and wear on the road infrastructures, already particularly tortuous and undersized.

When the two hypotheses are compared from an environmental point of view, with reference to the same vehicle (16t Lorry) and the same amount of waste transported (16t), it is possible to note that the GWP emissions generated in SCENARIO 1 are approximately $765 \mathrm{~kg} \mathrm{CO}$ eq (ki- lograms of carbon dioxide equivalent), while in SCENARIO 2 this value is $504 \mathrm{~kg} \mathrm{CO}$ eq. Consequently, it can be said that adopting the second hypothesis would reduce GWP emissions by an equal value of $34 \%$ (Figure 4 ).

Furthermore, regarding the vehicle selected for the study, it is useful to clarify that a specific comparison was made between some of the most common ones. Three vehicles were assessed: a 3.5 tonne van, a 16 tonne Lorry and a 21 tonne lorry traditionally used for waste collection. For each of these, the emitted $\mathrm{kg}$ of $\mathrm{CO}_{2}$ eq were considered, with reference to the unit value of $1 \mathrm{t} / 1 \mathrm{~km}$. The results demonstrate that the medium-large capacity vehicle (16t Lorry) is that with the lowest environmental impact, limiting transport-related emissions of GWP by roughly 75\% ( 0.30 instead of 1.3 $\mathrm{kg} \mathrm{CO}$ eq/t/km) compared to traditional vehicles (Figure 5). The results also confirm that the Reconstruction Commissioner's choice to use 16 tonne vehicles is consistent with the objective of limiting climate-altering emissions.

In conclusion, it must be noted that in order to arrive at the most economically, environmentally and socially sound choice, the above considerations must be placed in close relationship with other factors, such as the capacity of treatment structures, unit treatment costs and impacts on employment in specific territories. Factors that fall outside the scope of the present study.

\subsection{Guidelines and Operating Suggestions}

With reference to the purpose of the present study, i.e. 


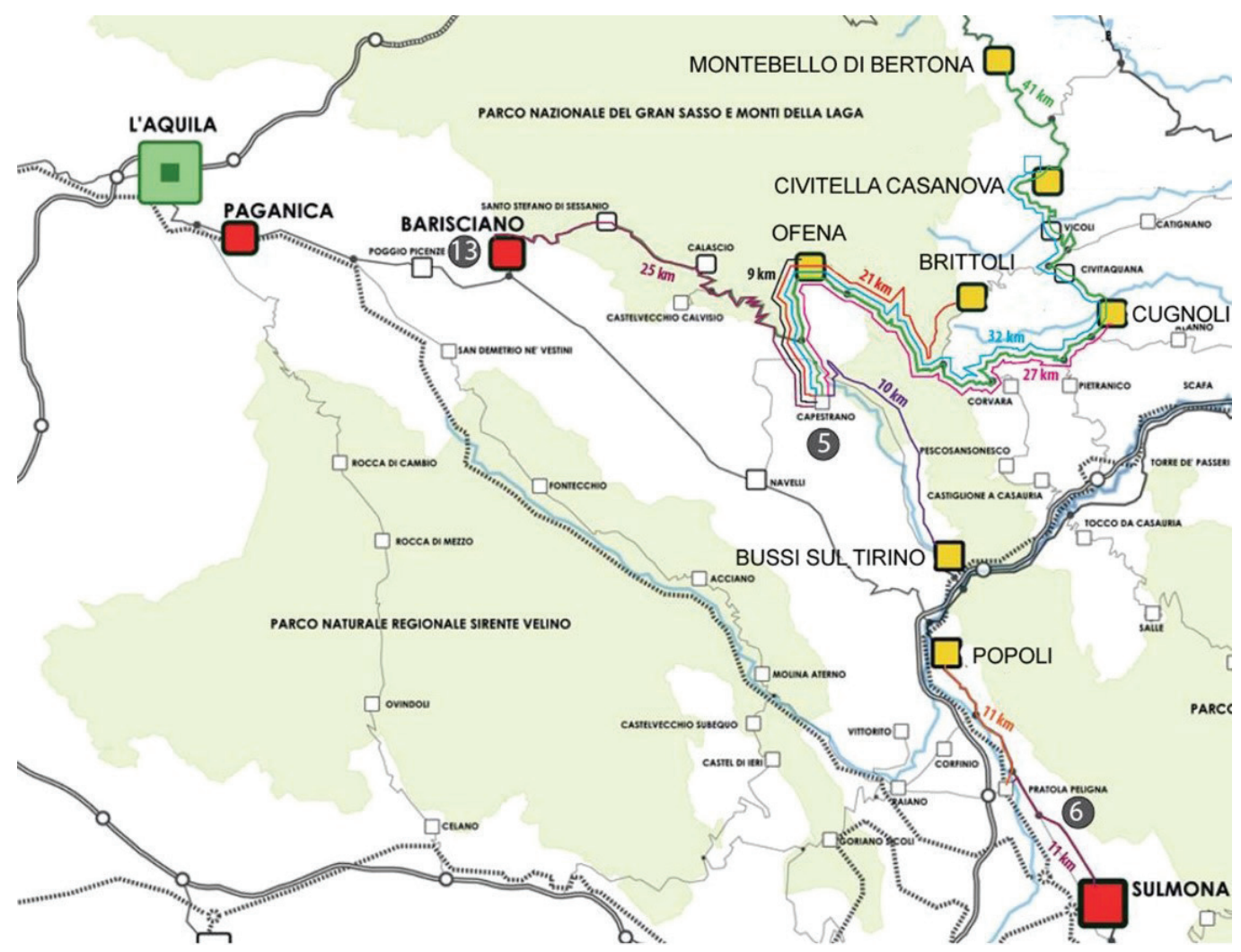

FIGURE 3: Identification of transportation flows for C\&DW produced by reconstruction works in the towns of Homogeneous Area 5 (in yellow). SCENARIO 2: storage by collection companies, based on the shortest distance criterion.

the sustainable management of rubble generated from the April 2009 L'Aquila earthquake, it could be helpful point out that a Presidential Ordinance (OPCM, 2011) also establishes minimum objectives for the reuse and/or recycling of debris. Firstly, historic building elements (worked pantiles, bricks, ceramics, stones, wood and metal) are to be directly reused, which requires on-site storage. Additionally, the same document also calls for the use of recycled aggregates, preferably derived from rubble treatment, for all public works concerning the construction of buildings, environmental restoration, backfill, dikes and embankments. This also involves the procurement of recycled aggregates to be used for infrastructures, underground services, roadways and public squares, as well as drainage, underpinning, screeds and structural and non-structural concrete elements in public and private buildings, compatible with legal requirements (Ferrari G., Morotti A., 2008).

Many of these indications, however, are lacking a quantitative reference and method for evaluating their effective implementation. For this reason, the decision was taken to develop a set of exhaustive guidelines to be added to the Implementing Technical Standards (NTA) accompanying Reconstruction Plans (PdR). These guidelines integrate the provisions of the aforementioned Presidential Ordinances with such environmental sustainability criteria as:

- Reducing emissions caused by the transportation of materials to/from sites;

- Reducing waste sent to landfills;

- Recycling and reusing C\&DW;
- Reducing the extraction of new raw materials.

One particular aspect of the procedure mentioned above involved the implementation of a C\&DW management system comprised of the following phases:

- Direct reuse in the same buildings or building blocks of non-polluted soil and rocks, duly identified and certified under the procedures outlined in Ministerial Decree $\mathrm{n}$. 161/2012 (Italian Ministry of the Environment, 2012). Recommended percentage: $75 \%$;

- Direct reuse in the same buildings or building blocks of recovered elements with historic and architectural value, such as recovered pantiles, bricks, ceramics, worked stone, worked wood. Recommended percentage: $90 \%$;

- Reuse of duly certified recycled inert aggregates (Italian Ministry of the Environment, 2005) in public works, in the design and construction of public infrastructures and environments for the creation of underground services, renovating public spaces, environmental restoration, backfill, dikes and embankments, to be procured in accordance with Abruzzo regional public works authorities. Recommended percentage 70\%;

- Reuse of certified recycled inert aggregates in private construction projects for drainage, backfill, underpinning and non-structural concrete works, to be procured from temporary storage sites or collection facilities in Abruzzo, in accordance with the criterion of the shortest distance from the site, and, if distances are equal, the shortest travel time, encouraging the grouping of 


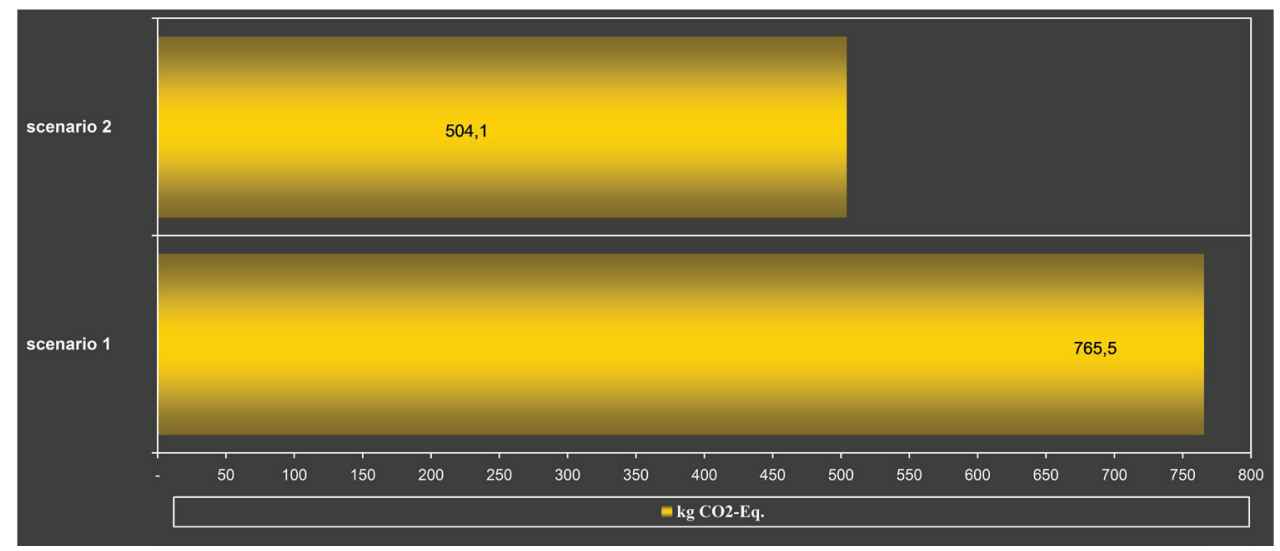

FIGURE 4: Simulation of $\mathrm{kg} \mathrm{CO}^{2}$ eq emissions potentially produced by the two scenarios, calculated based on vehicles carrying a maximum load of $16 \mathrm{t}$, with a full outbound load and an empty return (SIMAPRO calculation code, ECOINVENT database, IPCC method 2001 GWP 100a).

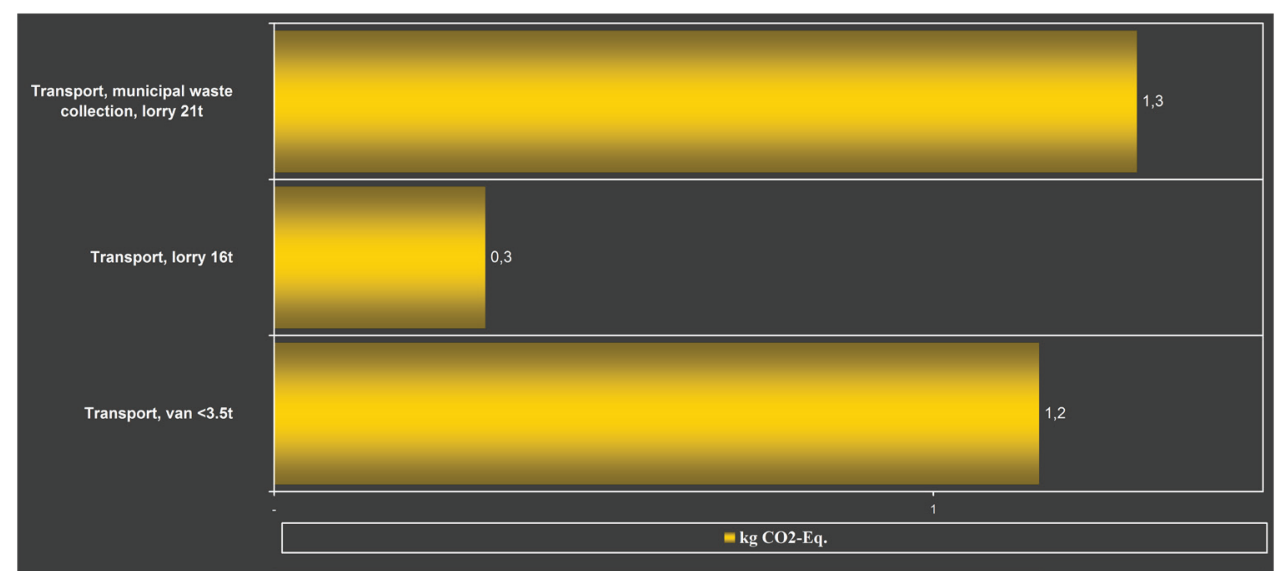

FIGURE 5: Simulation of $\mathrm{kg} \mathrm{CO}$ eq emissions potentially produced by various vehicles, with reference to the unit value of $1 \mathrm{t} / 1 \mathrm{~km}$ (SIMAPRO calculation code, ECOINVENT database, IPCC 2001 method GWP 100a).

orders from several sites. Recommended percentage $50 \%$;

- Accounting, as regards technical and economic assessments of the design and accounting of building repairs and/or construction aggregates for individual interventions, the quantity of C\&DW selected and assigned to the collection and disposal system by homogeneous category (according to the EWC code), the quality and quantity of elements of historical and architectural interest that are recovered and reused, the recycling materials and inert aggregates used, all with respect to the total of the same type, indicating the original producing Site, Facility or Company.

However, several factors affect the effective implementation of these objectives, including:

- The traceability of materials of historic or architectural interest (lapidarium) for reuse in reconstruction sites. When these elements are so numerous as to prevent their easy storage in individual sites because they block or hinder normal construction activities, they would need to be categorised to link them with their original building; when they are not reused, they should be made available to other building sites in the same town to reduce the amount of time materials are kept in storage areas and to limit the procurement of new materials;

- The availability of recyclable inert materials for the organisation of reconstruction programmes involving the rebuilding of a significant portion of the buildings at the same time, in order to optimise materials procurement; in similar cases, quick access to the following types of information would be very useful:

- The location of the treatment and recycling centre nearest the site;

- The availability of recycled materials at the structure or at alternative structures. This type of organisation and information could help reduce flows of transportation traffic in areas with especially winding and narrow roads, making it easier to locate the nearest supplier. Another evolution of this organisation model could also facilitate the application of shared transportation systems, in which a single vehicle could serve several sites in a single trip. As well, as analysed above, the environmental advantages of using recycled aggregates also depends on the distance 
between treatment plants and sites;

- The availability of specifications and unit prices. The qualification and certification of recycled aggregates (Italian Standardisation Body, 2008), as well as standardised pricing and the definition of adequate remuneration, would make it possible to compare and choose suppliers and encourage the use of recycled materials over new ones.

All issues will be specifically investigated in successive research activities.

\section{CONCLUSIONS}

Returning to a broader vision, it is important to highlight some aspects of the current supply system of quarry aggregates that, if re-examined in light of the considerations expressed above, could provide certain important food for thought.

A recent report by the Legambiente association (AA. VV., 2010) states that some $8,500,000 \mathrm{~m}^{3}$ of gravel and sand are extracted in Abruzzo each year. This puts the region at the top of the list in Italy in terms of aggregates produced per capita. So, aggregates recovered from rubble could be used to produce recycled materials, reducing extraction for both reconstruction and other construction and infrastructure activities in the region. This could also have a significant effect on reducing the amount of rubble consigned to landfills, postponing the landfill depletion problem and reducing disposal costs.

Accordingly, reusing rubble could represent a small piece of the region's economy, when the reconstruction and socio-economic renewal of the areas covered by Reconstruction Plans propose an innovative system based on the knowledge economy linked to recycling.

From this point of view, it is possible to identify certain specific actions:

- The creation of a Rubble Management Observatory to collect and manage information related to the collection, treatment, selection and redistribution of recyclable materials for reconstruction, and more generally, the reconversion of the agglomerate procurement system at the regional level;

- The creation of a Research Centre for pre-competition design, experimentation and development of construction products and systems based on recycling Construction \& Demolition Waste, available to public bodies and industries at the regional and national levels;

- The creation of a Business Incubator to train the people needed to manage the entrepreneurial and economic system related to the treatment and recycling of inert waste.

The opportunity to revamp the reconstruction and layout of urban outdoor areas and their technological underground works included in Reconstruction Plans could provide an opportunity to develop ad hoc design solutions and experimental applications. These pilots could fill the current knowledge gap between the experimental verification (in the laboratory) of residual uses of these recyclable materials and the effective services rendered by these materials when they are used in lieu of new materials for the development of long-term and reliable technological and building solutions.

As part of this vision, the planned creation and establishment of a Rubble Management Observatory to collect and monitor information related to the collection, treatment and distribution of recyclable materials for reconstruction, and more generally for the reconversion of the regional aggregate procurement system, could evolve to include the Provincial Waste Observatory planned in the Provincial Waste Management Plan for the monitoring, research and dissemination of good practices, support and development of actions disseminating Green Public Procurement processes, and study and research in the areas of recycling, eco-design, environmental audits and product lifecycles (Ma U., 2011).

\section{REFERENCES}

AA. VV. (2010). Debris zero year. Numbers, Delays, Responsibilities, Possible Solutions, Edizioni Legambiente (IT).

Albritton D. L., Meira-Filho L. G. (2001). Technical Summary, in Houghton J. T., Ding Y., Griggs D. J., Noguer M., Van Der Linden P. J., Xiaosu D., editors, Climate Change 2001: The Scientific Basis - Contribution of Working Group I to the Third Assessment Report of the Intergovernmental Panel on Climate Change (IPCC), Cambridge University Press, The Edinburgh Building Shaftesbury Road, Cambridge (UK).

Askarizadeh, L., Karbassi, A. R., Ghalibaf, M. B., \& Nouri, J. (2017). Debris management after earthquake incidence in ancient City of Ray. Global Journal of Environmental Science and Management.

Basti A. (2010). Life cycle design of building elements: selection criteria and case study application, in S. Hernandez, Brebbia C.A., \& De Wilde W.P., editors, Eco-Architecture 2010-Harmonisation between Architecture and Nature, WIT Press, Southampton (UK).

Braungart M., Mc Donough W. (2002). Cradle to Cradle: Remaking the Way We Make Things, North Point Press (US).

Brown C., Milke M., Seville E. (2011). Disaster waste management: A review article, Waste Management 31 (2011), 1085-1098.

Butera S., Christensen T.H, Astrup T.F. (2015). Life cycle assessment of construction and demolition waste management, Waste Management 44 (2015), 196-205.

Commissioner Delegated to Reconstruction, Decrees 18/2010, 49/2011 e 51/2011.

European Commission (2000). Decision 2000/532/EC, Hierarchical list of waste description.

European Commission (2005). Communication COM (2005) 670 Thematic Strategy for the sustainable use of resources.

European Commission (2008). Communication COM (2008) 400 Public procurement for a better environment.

European Commission (2008). Directive of Parliament and Council 2008/98/CE on Waste.

Fan H.C., Huang R., Hwang H., Chaod S.J. (2016). Properties of concrete incorporating fine recycled aggregates from crushed concrete wastes, Construction and Building Materials 112 (2016), 708-715.

Ferrari G., Morotti A. (2008). Use of concretes with recycled aggregates, "Recycling”, PEl Edizioni (IT).

Fischer C., Werge M., editors, (2009), EU as a Recycling Society, European Topic Centre on Resource and Waste Management, Copenhagen (DK).

Hischier R., Weidema B., editors, (2010), Implementation of Life Cycle Impact Assessment Methods, Swiss Centre for Life Cycle Inventories, St. Gallen $(\mathrm{CH})$.

Intergovernmental Panel on Climate Change (IPCC), (2001). IPCC Third Assessment Report. The Scientific Basis.

International Organization for Standardization (2006). ISO 14040. Environmental management - Life cycle assessment - Principles and framework. 
Italian Government (2006). Legislative Decree 152/2006, Environmental Standards.

Italian Government (2009). Decree law 39/2009, Urgent interventions in favor of populations affected by seismic events in the Abruzzo region in April 2009.

Italian Government (2010). Legislative Decree 205/2010, Provisions to implementing the Directive 2008/98/EC of the European Parliament on Waste.

Italian Government (2016). Legislative Decree 50/2016, Implementation of European Directives 2014/23/EU, 2014/24/EU and $2014 / 25 / E U$ on the award of public contracts and on the procurement procedures relating to works, services and supplies.

Italian Ministry of Environment (2003). Decree 203/2003, Standards for public offices and owned companies to cover the annual requirement of manufactured and goods with products made from recycled material not less than $30 \%$.

Italian Ministry of Environment (2005). Explanatory circular 5205/2005, Indications for operation in the construction, road and environmental field under the DM 203/2003.

Italian Ministry of Environment (2012). Decree 161/2012, Rules governing the use of excavated land and rocks.

Italian Ministry of Environment (2015). Decree 4 December 2015, Adoption of minimum environmental criteria for the assignment of design services and works for the new construction, the renovation and maintenance of buildings and for the management of public administration yards.

Italian Prime Minister, (2011). Ordinances 3923/2011, 3942/2011, $3945 / 2011$.
Italian standardization body (2008). Rule UNI EN 13242/2008, Properties of aggregates obtained by natural or industrial process or recycled for non-bonded and bonded hydraulic binders, for use in civil engineering works and road construction.

Laraia R., editor, (2011). Special Waste Report 2011 Edition, Italian National Institute for Environmental Protection and Research, Rome (IT).

Lauritzen E.K. (1998). Emergency construction waste management, Safety Science 30 (1998), 45-53.

Ma U. (2011). No Waste, Managing sustainability in Construction, Gover Publishing Limited, Farnham.

Ossa A., García J.L., Botero E. (2016). Use of recycled construction and demolition waste (CDW) aggregates: A sustainable alternative for the pavement construction industry, Journal of Cleaner Production 135 (2016), 379-386.

Puthussery J.V., Kumar R., Garg A. (2017). Evaluation of recycled concrete aggregates for their suitability in construction activities: An experimental study, Waste Management 60 (2017), 270-276.

Sasao T. (2016). Cost and efficiency of disaster waste disposal: A case study of the Great East Japan Earthquake, Waste Management 58 (2016), 3-13.

Señas L., Priano C., Marfi S. (2016). Influence of recycled aggregates on properties of self-consolidating concretes, Construction and Building Materials 113 (2016), 498-505.

Silva A., Rosano M, Stockera L., Gorissen L. (2017). From waste to sustainable materials management: Three case studies of the transition journey, Waste Management 61 (2017), 547-557. 